\title{
Towards development of novel immunization strategies against leishmaniasis using PLGA nanoparticles loaded with kinetoplastid membrane protein-II
}

\author{
This article was published in the following Dove Press journal: \\ International Journal of Nanomedicine \\ 21 April 2012 \\ Number of times this article has been viewed
}

\author{
Diego M Santos' \\ Marcia W Carneiro' \\ Tatiana R de Moura' \\ Kiyoshi Fukutani' \\ Jorge Clarencio' \\ Manuel Soto ${ }^{2}$ \\ Socorro Espuelas 3,4 \\ Claudia Brodskyn ${ }^{1,5}$ \\ Aldina Barral ${ }^{1,5}$ \\ Manoel Barral-Netto 1,5 \\ Camila I de Oliveira ${ }^{1,5}$ \\ 'Centro de Pesquisas Gonçalo \\ Moniz, FIOCRUZ, Salvador, BA, \\ Brazil; ${ }^{2}$ Centro de Biología Molecular \\ Severo Ochoa, Consejo Superior \\ de Investigaciones Cientificas, \\ Departamento de Biologia Molecular, \\ Universidad Autonoma de Madrid, \\ Madrid; ${ }^{3}$ Departamento de Farmacia y \\ Tecnología Farmacéutica, ${ }^{4}$ Instituto de \\ Salud Tropical, Facultad de Farmacia, \\ Universidad de Navarra, Pamplona, \\ Spain; ${ }^{5}$ Instituto de Investigação em \\ Imunologia, Salvador, BA, Brazil
}

Background: Vaccine development has been a priority in the fight against leishmaniases, which are vector-borne diseases caused by Leishmania protozoa. Among the different immunization strategies employed to date is inoculation of plasmid DNA coding for parasite antigens, which has a demonstrated ability to induce humoral and cellular immune responses. In this sense, inoculation of plasmid DNA encoding Leishmania kinetoplasmid membrane protein-11 (KMP-11) was able to confer protection against visceral leishmaniasis. However, recently the use of antigen delivery systems such as poly(lactic-co-glycolic acid) (PLGA) nanoparticles has also proven effective for eliciting protective immune responses.

Methods: In the present work, we tested two immunization strategies with the goal of obtaining protection, in terms of lesion development and parasite load, against cutaneous leishmaniasis caused by L. braziliensis. One strategy involved immunization with plasmid DNA encoding L. infantum chagasi KMP-11. Alternatively, mice were primed with PLGA nanoparticles loaded with the recombinant plasmid DNA and boosted using PLGA nanoparticles loaded with recombinant KMP-11.

Results: Both immunization strategies elicited detectable cellular immune responses with the presence of both proinflammatory and anti-inflammatory cytokines; mice receiving the recombinant PLGA nanoparticle formulations also demonstrated anti-KMP-11 IgG1 and IgG2a. Mice were then challenged with L. braziliensis, in the presence of sand fly saliva. Lesion development was not inhibited following either immunization strategy. However, immunization with PLGA nanoparticles resulted in a more prominent reduction in parasite load at the infection site when compared with immunization using plasmid DNA alone. This effect was associated with a local increase in interferon-gamma and in tumor necrosis factor-alpha. Both immunization strategies also resulted in a lower parasite load in the draining lymph nodes, albeit not significantly.

Conclusion: Our results encourage the pursuit of immunization strategies employing nanobased delivery systems for vaccine development against cutaneous leishmaniasis caused by L. braziliensis infection.

Keywords: vaccine, nanoparticle, Leishmania, kinetoplastid membrane protein-11

\section{Introduction}

Correspondence: Camila I de Oliveir Centro de Pesquisas Gonçalo Moniz, FIOCRUZ, Rua Waldemar Falcão I2I, Candeal, Salvador BA, Brazil 40I96-7I0

Tel +557131762211

Fax +55 7I 3176 2279

Email camila@bahia.fiocruz.br
Leishmaniasis is a group of diseases caused by infection with unicellular protozoan parasites of the genus Leishmania, which are transmitted through the bite of an infected sand fly. Disease burden remains important, involving 88 countries and 350 million people at risk, with 500,000 new cases of visceral leishmaniasis and 1-1.5 million cases 
of cutaneous leishmaniasis per year. ${ }^{1}$ Multiple Leishmania species are known to cause disease; L. braziliensis inoculation into the skin leads to the development of an ulcer with elevated borders and a necrotic center. A chronic inflammatory response develops despite the paucity of parasites. In $1 \%-5 \%$ of patients, mucocutaneous leishmaniasis may develop, and in this case, extensive tissue destruction is observed. ${ }^{2}$ Species such as L. infantum chagasi multiply in the spleen and liver, causing visceral leishmaniasis. The disease may present with acute, subacute, or chronic evolution, but most infected individuals remain completely asymptomatic. ${ }^{3}$ The visceral form of leishmaniasis is associated with an estimated incidence of 59,000 deaths annually. ${ }^{4}$ The feasibility of preventing Leishmania infection through vaccination is supported by the fact that individuals who recover from a primary infection are resistant to overt clinical manifestations upon reinfection. In general, the key mediator of resistance to leishmaniasis is cellular immunity, whereby interferongamma (IFN- $\gamma$ ) produced by CD4+ Th1 cells promotes the oxidative burst in phagocytes that host the intracellular pathogen, promoting parasite killing. ${ }^{5,6}$

Vaccination against leishmaniasis has been pursued using different strategies, ranging from inoculation of virulent parasites (leishmanization) to immunization with killed parasite preparations, live attenuated parasites, or with recombinant proteins or plasmid DNA coding for defined Leishmania antigens. ${ }^{7,8}$ DNA vaccines encode a potent adjuvant, in the form of unmethylated dinucleotides, which are able to activate antigen-presenting cells through Toll-like receptor 9, stimulating the system towards a Th1-type response. DNA vaccination has also been tested in heterologous prime-boost vaccination regimes ${ }^{9}$ in which the immune system is primed with DNA and boosted with a different formulation of the corresponding antigen. This strategy proved effective in models of visceral ${ }^{10-12}$ and cutaneous leishmaniasis. ${ }^{13-15}$ However, the adjuvant effect can also be achieved by encapsulation of antigens into biodegradable and biocompatible particles. ${ }^{16}$ In this sense, immunization with antigen-loaded poly(lactic-co-glycolic acid) (PLGA) nanoparticles induced potent immune responses in different experimental models of disease. ${ }^{17-19}$ Similar and encouraging results have been described regarding encapsulation of Leishmania antigens and the development of leishmaniasis. ${ }^{20,21}$

The $11 \mathrm{kDa}$ kinetoplastid membrane protein (KMP-11) ${ }^{22}$ is a promising vaccine candidate against leishmaniasis because it is a strong inducer of IFN- $\gamma$ production by cells from cured patients ${ }^{23}$ and it is highly conserved among the trypanosomatids. ${ }^{24}$ DNA immunization with KMP-11 was able to confer protection against visceral leishmaniasis caused by $L$. donovan $i^{25}$ and against cutaneous leishmaniasis caused by $L$. major, when used in combination with interleukin (IL)-12. ${ }^{26}$ Given that there are few published studies regarding vaccine development against $L$. braziliensis, ${ }^{27}$ a species prevalent in Brazil and South America, we evaluated the ability of KMP-11 to confer protection against cutaneous leishmaniasis caused by L. braziliensis, employing two strategies. One strategy involved immunization with a naked plasmid DNA coding for KMP-11, whereas a parallel strategy comprised priming with PLGA nanoparticles loaded with a plasmid DNA encoding KMP-11 followed by PLGA nanoparticles loaded with the recombinant KMP-11 protein.

\section{Materials and methods Mice}

Female BALB/c mice (6- 8 weeks of age) were obtained from the animal facility at Centro de Pesquisas Gonçalo Moniz, FIOCRUZ. All mice were maintained under pathogen-free conditions. The local Ethics Committee on Animal Care and Utilization approved all procedures involving animals.

\section{Plasmid and recombinant protein purification}

The DNA insert containing the coding region of Leishmania KMP-11 was obtained after BamHI/SmaI digestion of the pQE-KMP-11 plasmid ${ }^{28}$ and was subcloned in the BamHI/ EcoRV sites of the pcDNA3 eukaryotic expression plasmid. Plasmid DNA (pcDNA3 and pcDNA3-KMP-11) was purified using an Endofree Plasmid Giga Kit (Qiagen, Valencia, CA) according to the manufacturer's instructions. The recombinant plasmid, pQE30-KMP-11, ${ }^{28}$ was transformed into Escherichia coli. Recombinant protein expression was performed as described previously. ${ }^{29}$ Nonrecombinant pcDNA3, pcDNA3KMP-11, and recombinant KMP-11 protein were encapsulated into PLGA nanoparticles, as described below.

\section{Preparation and characterization of KMP-I I nanoparticles}

Nanoparticles were prepared by employing a solvent evaporation process using a Total Recirculation One-Machine System, which has been used previously for the encapsulation of DNA into PLGA particles..$^{30}$ Briefly, $100 \mathrm{mg}$ of PLGA Resomer 503 copolymer (4\% w/v, polylactic:glycolic acid ratio 50:50, molecular weight $34 \mathrm{kDa}$, carrying uncapped 
hydroxyl and carboxyl, Boehringer Ingelheim, Ingelheim, Germany) and $10 \mathrm{mg}$ of cationic lipid 1,2-dioleoyl-snglycero-3-ethylphosphocholine (DOTAP, chloride salt, Avanti Polar Lipids Inc, Alabaster, AL) were dissolved in $2.5 \mathrm{~mL}$ dichloromethane and injected through a needle (inner diameter $0.17 \mathrm{~mm}$ ) under a turbulent regime $(50 \mathrm{~mL} /$ minute) onto a Pluronic F68 ${ }^{\circledR}$ solution $(500 \mu \mathrm{L} 6 \% \mathrm{w} / \mathrm{v}$, Sigma-Aldrich, St Louis, MO) containing $2 \mathrm{mg}$ of either recombinant KMP-11 protein, non-recombinant pcDNA3, or recombinant pcDNA3-KMP-11. This $\mathrm{W}_{1} / \mathrm{O}$ emulsion was forced to circulate through the system for 4 minutes in order to homogenize the emulsion droplet size. The preformed emulsion was injected into the outer water $\left(\mathrm{W}_{2}\right)$ phase, ie, $15 \mathrm{~mL}$ of polyvinyl alcohol $0.5 \% \mathrm{w} / \mathrm{v}(87 \%$ hydrolyzed, molecular weight 115,000; BDH Prolabo; VWR International, Radnor, PA) under a constant pump flow. The turbulent injection resulted in formation of a double emulsion $\left(\mathrm{W}_{1} / \mathrm{O} / \mathrm{W}_{2}\right)$ that was homogenized by circulation through the system for 8 minutes. The final emulsion was magnetically stirred to allow solvent evaporation and particle formation. The resulting particles (recombinant KMP-11-loaded, nonrecombinant pcDNA3-loaded, pcDNA3-KMP-11-loaded nanoparticles) or unloaded nanoparticles were centrifuged $(9300 \times \mathrm{g})$, washed, freeze-dried, lyophilized and stored at $-20^{\circ} \mathrm{C}$. Nanoparticle size and zeta potential were determined, respectively, by photon correlation spectroscopy and laser Doppler velocimetry using a Zetasizer Nano Series (Malvern Instruments, Worcestershire, UK) after dilution of the samples in distilled water or $\mathrm{KCl}(1 \mathrm{mM})$. All measurements were performed in triplicate. The recombinant KMP-11 protein content of the recombinant KMP-11-loaded nanoparticles was determined using the Micro BCA protein assay (Pierce, Rockford, IL) following the manufacturer's instructions. The colorimetric reaction was measured in a spectrophotometer at $562 \mathrm{~nm}$ and compared with the absorbance obtained with nonencapsulated recombinant KMP-11. For this purpose, control calibration curves $(1.5-50 \mu \mathrm{g} / \mathrm{mL})$ were prepared using recombinant KMP-11 dissolved in $\mathrm{NaOH} 0.1 \mathrm{~N}$. The amount of plasmidial pcDNA3-KMP-11 DNA or nonrecombinant pcDNA3 loaded into the nanoparticles was estimated using a fluorimetric assay (PicoGreen ${ }^{\circledR}$ dsDNA quantitation kit; Molecular Probes, Eugene, OR), following the manufacturer's instructions. The amount of encapsulated recombinant KMP-11 in the nanoparticles was $3.5 \pm 0.5$ per mg of recombinant KMP-11-loaded particles; nonrecombinant pcDNA3-loaded nanoparticles contained $7.2 \pm 0.7 \mu \mathrm{g}$ of pcDNA3 per mg of particles, and pcDNA3-KMP-11-loaded nanoparticles contained $6.4 \pm 1.2 \mu \mathrm{g}$ of pcDNA3-KMP-11 DNA per mg of particles.

\section{Immunization with KMP-I I plasmid DNA or recombinant KMP-I I-loaded PLGA nanoparticles}

$\mathrm{BALB} / \mathrm{c}$ mice (in groups of six) received $100 \mu \mathrm{g}$ of nonrecombinant pcDNA3 or pcDNA3-KMP-11 in saline into the right quadriceps on days 0,14 , and 28 . Alternatively, mice were primed with pcDNA3-KMP-11-loaded nanoparticles (containing $30 \mu \mathrm{g}$ of pcDNA3-KMP-11), injected into the left ear dermis, and were boosted 21 days later with recombinant KMP-11-loaded nanoparticles (containing $10 \mu \mathrm{g}$ of recombinant KMP-11) in the presence of $25 \mu \mathrm{g}$ of each CpG oligodeoxynucleotide (5'-TCAGCGTTGA-3' and 5'-GCTAGCGTTAGCGT-3') (E-OLIGOS). ${ }^{31}$ Control mice were primed with nonrecombinant pcDNA3-loaded nanoparticles (containing $30 \mu \mathrm{g}$ of pcDNA3), also injected in the left ear dermis, and were boosted with unloaded (empty) nanoparticles $+\mathrm{CpG}$. Samples of immune sera were collected 2 weeks after the last immunization.

\section{Cytokine detection in mice immunized with KMP-I I plasmid DNA or with recombinant KMP-I I-loaded nanoparticles}

$\mathrm{BALB} / \mathrm{c}$ mice were immunized as described above. Two weeks after the last immunization, the mice were euthanized, and single-cell suspensions of lymph nodes draining the immunization site (popliteal for DNA-injected mice and retroaxillary for PLGA nanoparticle-injected mice) were prepared aseptically. Briefly, the draining lymph nodes were homogenized in RPMI 1640 medium and the cells were resuspended in RPMI medium supplemented with $2 \mathrm{mM}$ L-glutamine, $100 \mathrm{U} / \mathrm{mL}$ penicillin, $100 \mu \mathrm{g} / \mathrm{mL}$ streptomycin, $10 \%$ fetal calf serum (all from Invitrogen, Carlsbad, CA) and $0.05 \mathrm{M} \beta$-mercaptoethanol. Cell suspensions were stimulated with recombinant KMP-11 $(10 \mu \mathrm{g} / \mathrm{mL})$ for 48 hours. Culture supernatants were harvested and the presence of cytokines was assayed using a Th1/Th2 cytokine cytometric bead array (BD Biosciences, Franklin Lakes, NJ), which detects murine IL-2, IL-4, IL-5, IFN- $\gamma$, and tumor necrosis factor-alpha (TNF- $\alpha$ ), following the manufacturer's instructions. Data were acquired and analyzed using a FACSort flow cytometer (BD Immunocytometry, San Jose, CA) and CBA analysis software (Becton-Dickinson, Franklin Lakes, NJ). 


\section{Humoral immune response in mice immunized with KMP-II plasmid DNA or with recombinant KMP-II-loaded nanoparticles}

Enzyme-linked immunosorbent assay microplates were coated overnight at $4^{\circ} \mathrm{C}$ with recombinant KMP-11 $(1 \mu \mathrm{g} / \mathrm{mL})$ in coating buffer $\left(\mathrm{NaHCO}_{3} 0.45 \mathrm{M}, \mathrm{Na}_{2} \mathrm{CO}_{3} 0.02 \mathrm{M}\right.$, pH 9.6). After washing with phosphate-buffered saline-Tween, the wells were blocked with phosphate-buffered salineTween plus $5 \%$ dried skim milk for one hour at $37^{\circ} \mathrm{C}$. The wells were incubated overnight with sera (diluted 1:100) from mice immunized with pcDNA3-KMP-11 only or with pcDNA3-KMP-11-loaded nanoparticles followed by recombinant KMP-11-loaded nanoparticles, in the presence of CpG. After further washings, wells were incubated with alkaline phosphatase-conjugated antimouse IgG antibody (Promega, Madison, WI) diluted (1:2500) in phosphate-buffered salineTween, for one hour at $37^{\circ} \mathrm{C}$. Following another washing cycle, wells were developed with p-nitrophenylphosphate in sodium carbonate buffer at $\mathrm{pH} 9.6$ with $1 \mathrm{mg} / \mathrm{mL}$ of $\mathrm{MgCl}_{2}$. The absorbance was recorded at $405 \mathrm{~nm}$. Serum IgG subclasses were determined using antimouse IgG1 or IgG2a alkaline phosphatase conjugates (Sigma-Aldrich).

\section{Challenge with L. braziliensis and sand fly saliva}

L. braziliensis promastigotes (strain $\mathrm{MHOM} / \mathrm{BR} / 01 /$ BA788 ${ }^{32}$ ) were grown in Schneider medium (Sigma-Aldrich) supplemented with $100 \mathrm{U} / \mathrm{mL}$ of penicillin, $100 \mu \mathrm{g} / \mathrm{mL}$ of streptomycin, and $10 \%$ heat-inactivated fetal calf serum (all from Invitrogen). Stationary-phase promastigotes were used in all experiments. Adult Lutzomyia intermedia sand flies were captured in Corte de Pedra, Bahia, and used for dissection of salivary glands. Preparation of salivary gland sonicate was conducted as described elsewhere. ${ }^{33}$ The level of lipopolysaccharide contamination of salivary gland sonicate preparations was determined using a commercially available Limulus amebocyte lysate chromogenic kit (QCL-1000, Lonza Biologics, Newington, $\mathrm{NH}$ ); the lipopolysaccharide concentration was $<0.1 \mathrm{ng} / \mathrm{mL}$. Two weeks after the last immunization, all groups of mice were challenged in the dermis of the right ear with L. braziliensis promastigotes + salivary gland sonicate, as described earlier. ${ }^{34}$ The progress of infection was monitored weekly, for 10 weeks, by measuring of ear swelling with a digital caliper (Thomas Scientific, Swedesboro, NJ). Parasite load in the infected ear and in its draining lymph nodes was determined as described below.

\section{Parasite load estimate}

Parasite load was determined using a quantitative limitingdilution assay as described elsewhere. ${ }^{32}$ Briefly, infected ears and lymph nodes draining the infection site were aseptically excised at five weeks following infection with L. braziliensis + salivary gland sonicate and homogenized in Schneider medium (Sigma-Aldrich). The homogenates were serially diluted in Schneider medium supplemented as before and seeded into 96-well plates containing biphasic blood agar (Novy-Nicolle-McNeal) medium. The number of viable parasites was determined from the highest dilution at which the promastigote could be grown out after up to 2 weeks of incubation at $25^{\circ} \mathrm{C}$.

\section{Evaluation of cellular immune response after challenge by flow cytometry}

Five weeks following infection with $L$. braziliensis + salivary gland sonicate, the mice were euthanized, and single-cell suspensions of lymph nodes draining the infection site were prepared as described above. Cells were activated in the presence of anti-CD3 $10 \mu \mathrm{g} / \mathrm{mL}$ and anti-CD28 $10 \mu \mathrm{g} / \mathrm{mL}$ or with Con A $5 \mu \mathrm{g} / \mathrm{mL}$ (Amersham Biosciences, Piscataway, NJ), and were later incubated with Brefeldin A $10 \mu \mathrm{g} / \mathrm{mL}$ (Sigma-Aldrich). Cells were blocked with anti-Fc receptor antibody (2.4G2) and were double-stained simultaneously with antimouse surface CD4 (H129.19) conjugated to FITC. For intracellular staining of cytokines, cells were permeabilized using Cytofix/Cytoperm (BD Biosciences) and incubated with the anticytokine antibodies conjugated to PE:IFN- $\gamma$ (XMG1.2), IL-4 (BVD4-1D11), and IL-10 (JES5-16E3). The isotype controls used were rat IgG2b (A95-1) and rat IgG2a (R35-95). Data were collected and analyzed using CELLQuest software and a FACSort flow cytometer (Becton-Dickinson). The steady-state frequencies of cytokine positive cells were determined using lymph node cells from control mice.

\section{Cytokine expression at challenge site}

Five weeks following infection with L. braziliensis + salivary gland sonicate, the mice were euthanized, infected ears were excised and placed into RLT buffer, and total RNA was extracted using the RNeasy Protect Mini Kit (Qiagen) according to the manufacturer's instructions. Ear tissue was mechanically lysed with ceramic beads in a MagNALyzer ${ }^{\circledR}$ instrument (Roche Molecular Systems, Pleasanton, CA), according to the manufacturer's instructions. The resulting tissue lysates were then employed in downstream total RNA extraction. The resulting RNA was resuspended in $20 \mu \mathrm{L}$ 
of water and stored at $-80^{\circ} \mathrm{C}$ until use. cDNA synthesis was performed after reverse transcription (Im Prom-II ${ }^{\mathrm{TM}}$ reverse transcription system; Promega) of RNA. Real-time polymerase chain reaction was performed in triplicate on the ABI Prism 7500 (Applied Biosystems, Foster City, CA); thermal cycle conditions consisted of a two-minute initial incubation at $50^{\circ} \mathrm{C}$ followed by ten-minute denaturation at $95^{\circ} \mathrm{C}$, and 50 cycles at $95^{\circ} \mathrm{C}$ for 15 seconds and $60^{\circ} \mathrm{C}$ for one minute each. Each sample and the negative control were analyzed in triplicate for each run. The comparative method was used to analyze gene expression. Cytokine cycle threshold $\left(\mathrm{C}_{\mathrm{t}}\right)$ values were normalized to GAPDH expression, as determined by $\Delta \mathrm{C}_{\mathrm{t}}=\mathrm{C}_{\mathrm{t} \text { (cytokine) }}-\mathrm{C}_{\mathrm{t}(\mathrm{GAPDH})}$. Fold change was determined by $2^{-\Delta \Delta \mathrm{Ct}}$, where $\Delta \Delta \mathrm{C}_{\mathrm{t}}=\Delta \mathrm{C}_{\mathrm{t} \text { (experimental) }}-\Delta \mathrm{C}_{\mathrm{t}(\text { control). }}{ }^{35}$ The primers employed herein are described elsewhere. ${ }^{33}$

\section{Statistical analysis}

Data are presented as the mean \pm the standard error. The significance of the results was calculated using nonparametric statistical tests, ie, the two-sided Mann-Whitney test for comparisons between two groups. Analyses were conducted using Prism software (version 5.0; GraphPad Software, Inc, San Diego, CA). Differences were considered statistically significant at $P \leq 0.05$.

\section{Results \\ Cellular immune response after immunization with plasmid DNA \pm recombinant PLGA nanoparticles}

Initially we investigated the anti-KMP-11 cellular immune response induced by immunization using the different strategies. As shown in Figure 1, in vitro stimulation of draining lymph node cells from mice immunized with pcDNA3-KMP-11 induced a significantly higher production of IL-2 (Figure 1A), IFN- $\gamma$ (Figure 1B), TNF- $\alpha$ (Figure 1C), IL-4 (Figure 1D), and IL-5 (Figure 1E), when compared with control mice.

The recombinant nanoparticles used herein had a mean size of 300-450 nm, irrespective of the type of encapsulated antigen (DNA or protein). The mean zeta potential values were between $20 \mathrm{mV}$ and $30 \mathrm{mV}$, indicating a positive charge at $\mathrm{pH} 7.4$, and independently of the nanoparticle load (recombinant KMP-11 or pcDNA3-KMP-11). Recombinant KMP-11 content per mg of recombinant particle was $3.5 \pm 0.5 \mu \mathrm{g}$. Regarding plasmid DNA content, one mg of recombinant particles contained $7.2 \pm 0.7 \mu \mathrm{g}$ and $6.4 \pm 1.2 \mathrm{ug}$ of wild-type and pcDNA3-KMP-11, respectively. When mice were immunized with the recombinant nanoparticle formulations, IL-2 (Figure $2 \mathrm{~A}$ ) and IFN- $\gamma$ (Figure 2B) production was also increased. However, in this case, TNF- $\alpha$ levels were significantly higher (Figure 2C), whereas IL-4 (Figure 2D) and IL-5 (Figure 2E) production was similar to that detected in control mice.

\section{Humoral immune response on immunization with plasmid DNA or PLGA nanoparticles}

We also probed for the anti-KMP-11 humoral immune response induced by immunization with the different strategies. We did not detect anti-KMP-11 antibodies in mice immunized with either pcDNA3-KMP-11 or with nonrecombinant pcDNA3 (data not shown). However, mice inoculated with pcDNA3-KMP-11-/recombinant KMP-11-loaded nanoparticles $+\mathrm{CpG}$ developed a strong and antigen-specific humoral immune response (Figure 3A). IgG1 and IgG2a subclasses (Figure 3B) were detected in immune sera which could be associated with the presence of both IL-4/IL-5 and IFN- $\gamma /$ TNF- $\alpha$, as seen upon restimulation of draining lymph node cells (Figure 2).

\section{Outcome of L. braziliensis infection in mice immunized with plasmid DNA or PLGA formulations}

Next, we investigated the outcome of infection with L. braziliensis, in the presence of sand fly saliva. Immunization with pcDNA3-KMP-11 did not alter the course of clinical disease upon a live challenge (Figure 4A), with both immunized and control mice displaying the same outcome followed by spontaneous healing. However, mice inoculated with pcDNA3-KMP-11 had a significantly lower $(P<0.05)$ parasite load at the ear dermis 5 weeks after infection when compared with control mice (Figure 4B). A similar finding was observed in draining lymph nodes (Figure 4C), although the difference was not significant.

Interestingly, immunization with pcDNA3-KMP-11-/ recombinant KMP-11-loaded nanoparticles + CpG also did not prevent development of disease (Figure 5A) when compared with control animals. Of note, the ear thickness of mice immunized with recombinant nanoparticles was slightly smaller when compared with controls (Figure 5A) at 5 weeks after infection. Similar to results obtained upon DNA immunization (Figure 4B), immunization with the recombinant formulations also significantly $(P<0.05)$ decreased parasite load in the ear dermis (Figure 5B). Interestingly, parasite load in draining lymph nodes was also lower when compared with control mice (Figure 5C). 


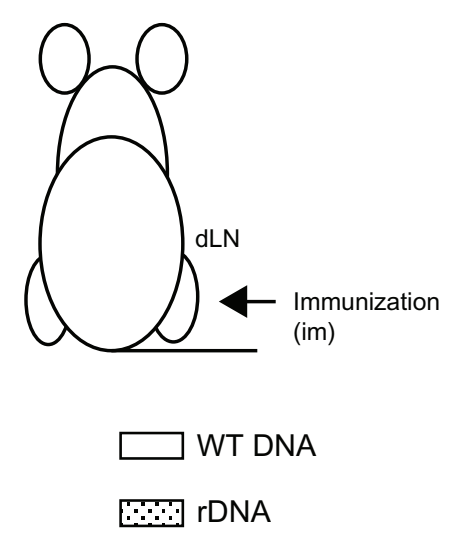

B

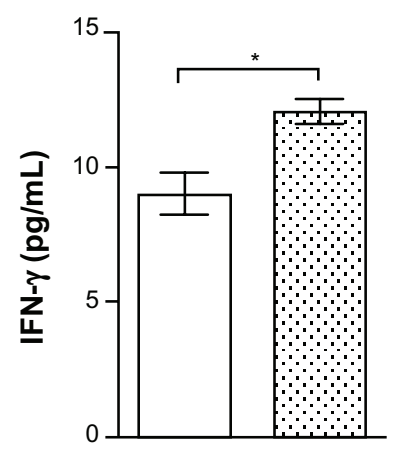

D

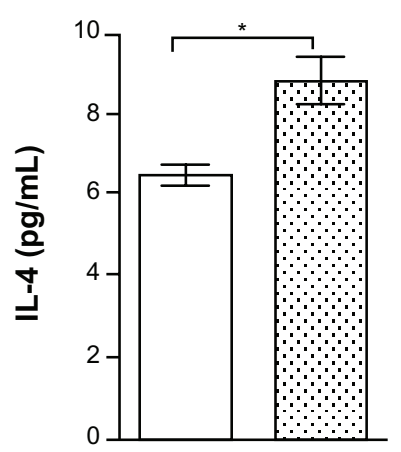

A

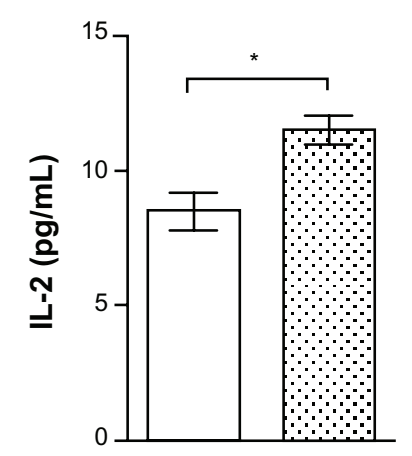

C

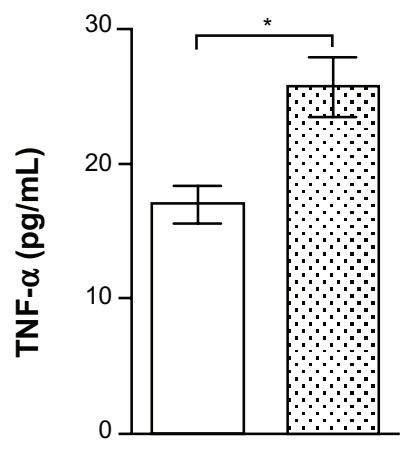

E

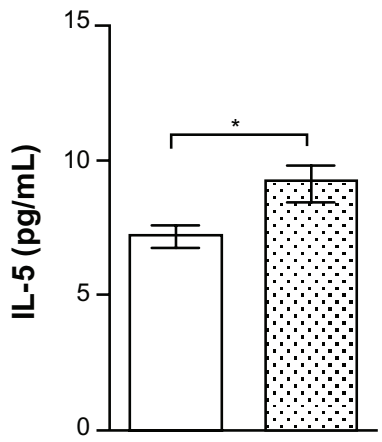

Figure I Cytokine production in mice immunized with a plasmid DNA encoding KMP-II.

Notes: BALB/c mice were immunized with nonrecombinant pcDNA3 (open bars) or with pcDNA3-KMP-II (closed bars), as described. Two weeks after the last immunization, draining lymph nodes were collected and the cells were restimulated with recombinant KMP-II. The presence of cytokines in culture supernatants was determined by flow cytometry, using a ThI-Th2 cytometric bead array. Data are presented as the mean \pm standard error and are from two independent experiments, each performed with six mice per group. $* P<0.05$

Abbreviations: IFN, interferon; IL, interleukin; KMP-I I, kinetoplastid membrane protein-I I; TNF, tumor necrosis factor.

\section{Cytokine production in situ after L. braziliensis + salivary gland sonicate challenge}

Because both immunization strategies significantly reduced parasite load at the infection site, we probed for cytokine expression therein 5 weeks after infection. Remarkably, mice immunized with pcDNA3-KMP-11 showed upregulation in both IFN- $\gamma$ and IL-10 expression (Figure 6A) at the infection site; IFN- $\gamma$ expression was upregulated by approximately 5 -fold in comparison with control animals, whereas this increase was about 15 -fold for IL-10. TNF- $\alpha$ expression was not detected in mice immunized with pcDNA3-KMP-11. On the other hand, mice immunized with pcDNA3-KMP-11-/recombinant 


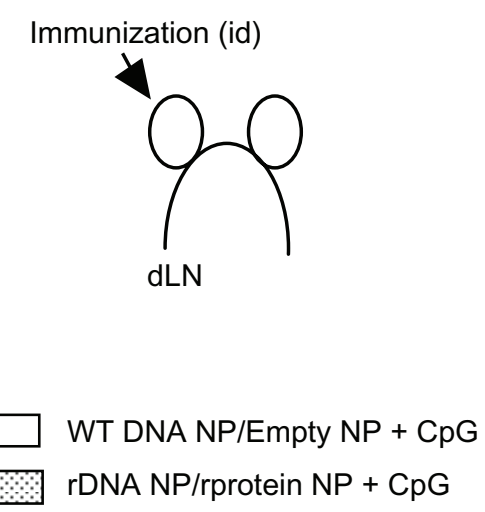

B

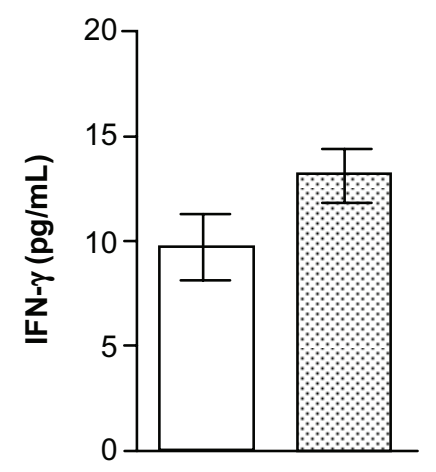

D

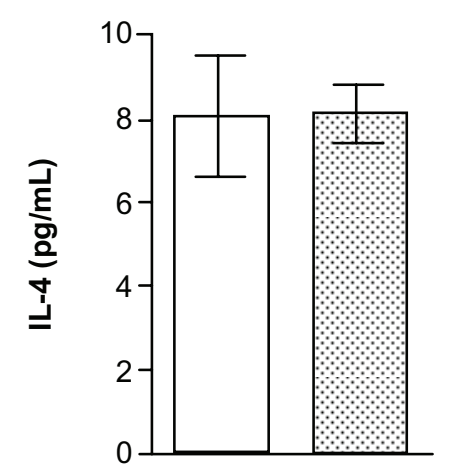

A

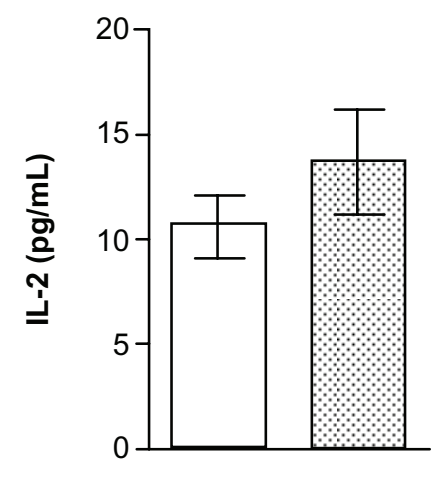

C

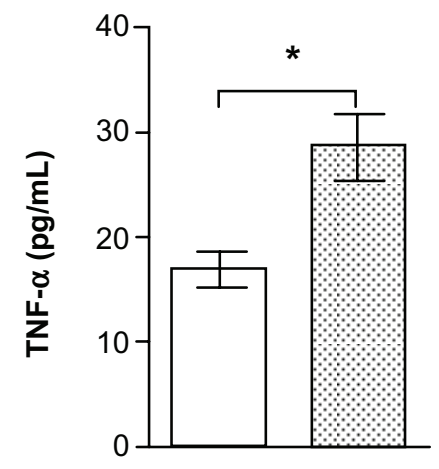

E

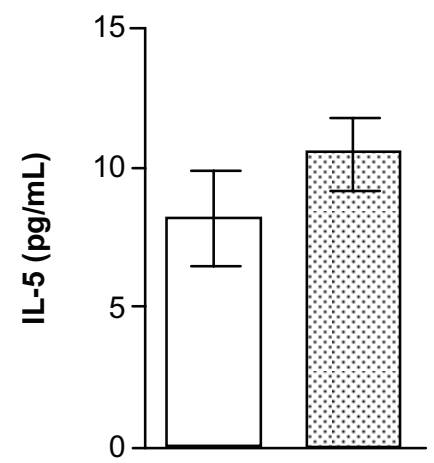

Figure 2 Cytokine production in mice immunized with KMP-I I-loaded nanoparticles.

Notes: Control BALB/c mice were immunized with nonrecombinant pcDNA3-loaded nanoparticles followed by unloaded (empty) nanoparticles + CpG (open bars). Experimental BALB/c mice were immunized with pcDNA3-KMP-II-loaded nanoparticles followed by recombinant KMP-II-loaded nanoparticles + CpG (closed bars). Two weeks after the last immunization, draining lymph nodes were collected and cells were restimulated with recombinant KMP-II. The presence of cytokines in culture supernatants was determined by flow cytometry, using a Th I-Th2 cytometric bead array. Data are presented as the mean \pm standard error and are from two independent experiments, each performed with six mice per group. $* P<0.05$.

Abbreviations: IFN, interferon; IL, interleukin; KMP-I I, kinetoplastid membrane protein-I I;TNF, tumor necrosis factor.

KMP-11-loaded nanoparticles + CpG showed a more moderate upregulation in IFN- $\gamma$ and TNF- $\alpha$ expression (Figure 6B) at the infection site. In contrast with mice immunized using pcDNA3-KMP-11, challenge infection with parasites induced downregulation in IL-10 expression in the mice receiving recombinant PLGA nanoparticles (Figure 6B).
Upon challenge with L. braziliensis + salivary gland sonicate, mice immunized with pcDNA3-KMP-11 or with the recombinant nanoparticle formulations also displayed a lower parasite load within the draining lymph nodes (Figure 4C and $5 \mathrm{C}$, respectively). Therefore, we also evaluated the frequency of cytokine-secreting cells therein. After infection, mice immunized 

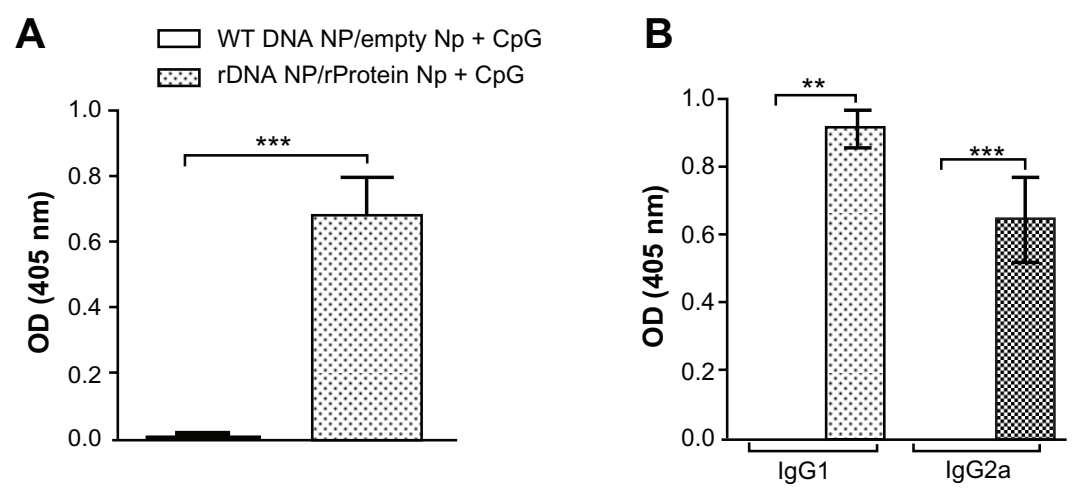

Figure 3 Humoral immune response in mice immunized with KMP-I I-loaded nanoparticles.

Notes: Control BALB/c mice were immunized with nonrecombinant pcDNA3-loaded nanoparticles followed by unloaded nanoparticles + CpG (open bars). Experimental BALB/c mice were immunized with pcDNA3-KMP-II-loaded nanoparticles followed by recombinant KMP-II-loaded nanoparticles + CpG (closed bars). (A) Presence of anti-KMP-I I IgG antibodies was determined by enzyme-linked immunosorbent assay. IgG subclasses present were determined by enzyme-linked immunosorbent assay using $\operatorname{lgGI}$ and IgG2a conjugates (B).Data are presented as the mean \pm standard error and are from two independent experiments. $* P<0.0 \mathrm{I}$

Abbreviation: KMP-II, kinetoplastid membrane protein-II.

with pcDNA3-KMP-11 displayed a lower percentage of CD4+ IFN- $\gamma+($ Figure 7A), CD4+ IL-4+(Figure 7B), and CD4+IL-10+ (Figure 7C) cells when compared with controls.

Cells from mice immunized with pcDNA3-KMP-11-/ recombinant KMP-11-loaded nanoparticles + CpG also displayed a decreased frequency of CD4+ IFN- $\gamma+$ T cells (Figure 8A), after infection. In these animals, the percentage of CD4+ IL-4+ (Figure 8B) and CD4+ IL-10+ cells (Figure 8C) was similar (Figure 7B) or slightly higher (Figure 7C) when compared with controls. Similar results

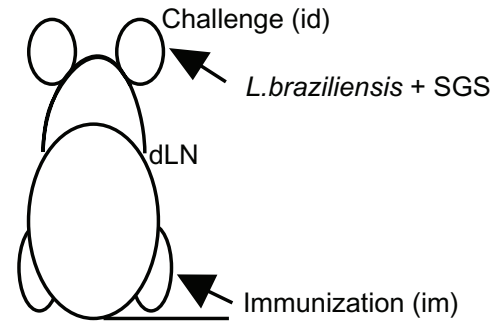

A
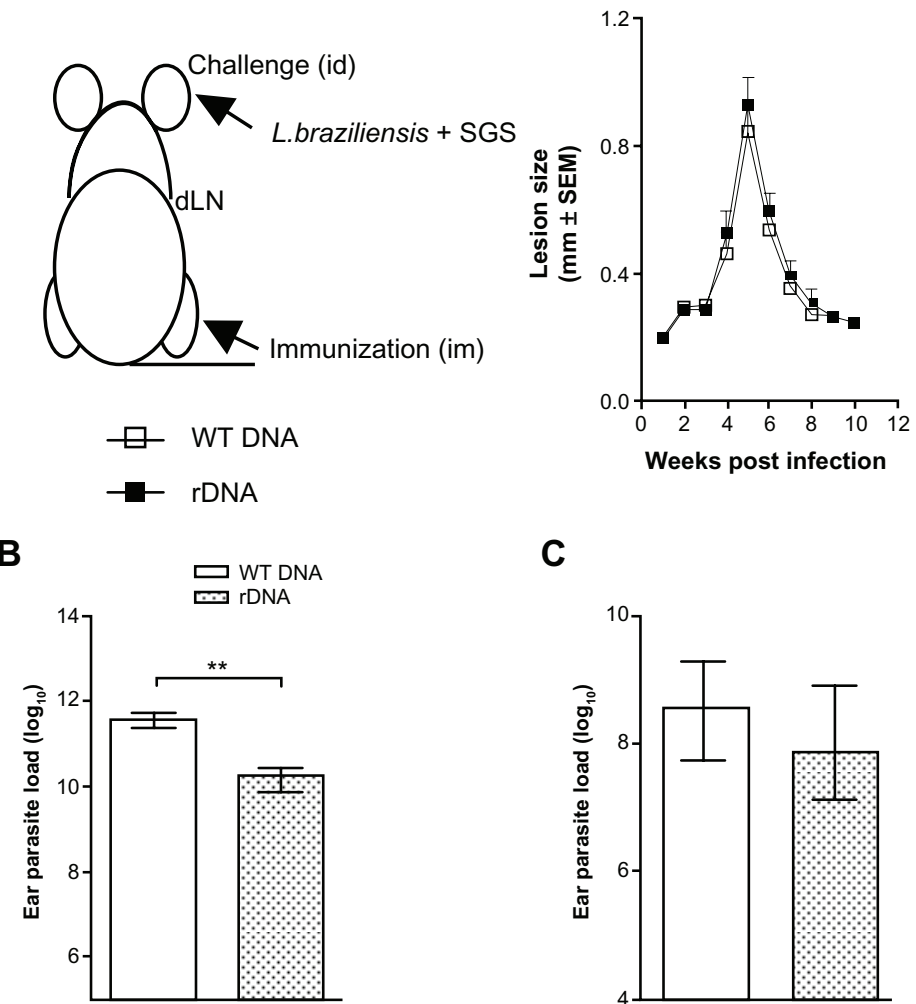

C

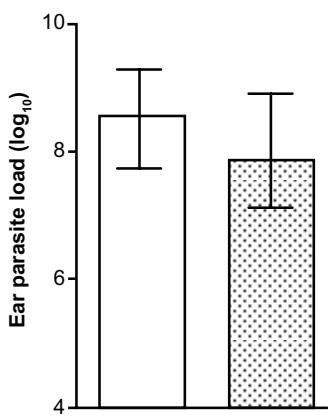

Figure 4 Lesion development and parasite load in mice immunized with a plasmid DNA encoding KMP-II, following a live challenge with parasites.

Notes: BALB/c mice were immunized with nonrecombinant pcDNA3 (open bars) or with pcDNA3-KMP-II (closed bars), as described. Two weeks after the last immunization, mice were infected in the ear dermis with Leishmania braziliensis + salivary gland sonicate. The course of lesion development was monitored weekly (A), parasite load in the ear (B), and in draining lymph nodes (C) was determined 5 weeks following infection. Data are presented as the mean \pm standard error and are from two independent experiments. $* * P<0.01$.

Abbreviations: KMP-II, kinetoplastid membrane protein-II; SGS, salivary gland sonicate. 


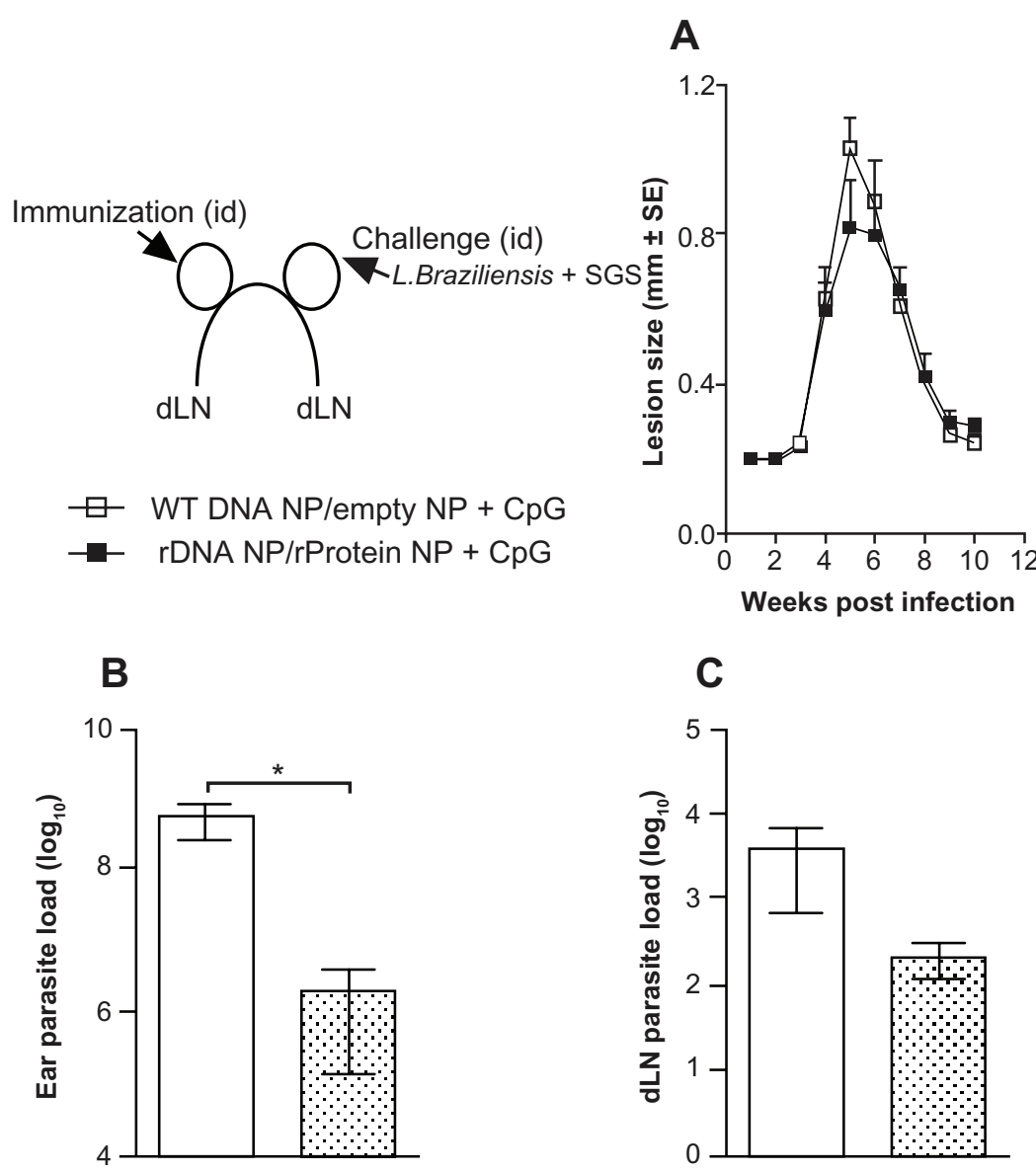

Figure 5 Lesion development and parasite load in mice immunized with KMP-I I-loaded nanoparticles, following a live challenge with parasites.

Notes: Control BALB/c mice were immunized with nonrecombinant pcDNA3-loaded nanoparticles followed by unloaded nanoparticles + CpG (open bars). Experimental BALB/c mice were immunized with pcDNA3-KMP-II-loaded nanoparticles followed by recombinant KMP-II-loaded nanoparticles + CpG (closed bars). Two weeks after the last immunization, mice were infected in the ear dermis with Leishmania braziliensis + salivary gland sonicate. The course of lesion development was monitored weekly (A). Parasite load in the ear (B) and in draining lymph nodes (C) was determined 5 weeks following infection. Data are presented as the mean \pm standard error and are from two experiments. $* P<0.05$.

Abbreviations: KMP-I I, kinetoplastid membrane protein-I I; SGS, salivary gland sonicate.

were found for cytokine-secreting CD8+ T cells (data not shown).

\section{Discussion}

In the present work, we evaluated two immunization strategies for their potential to elicit protective immune responses in an experimental model of infection. One strategy consisted of immunization with plasmid DNA and the other involved use of PLGA nanoparticles loaded with plasmid DNA or with the respective recombinant protein. We hypothesized that encapsulation would protect the antigen from degradation and, in parallel, that a heterologous prime-boost strategy would enhance the immune response.

Herein, immunization of BALB/c mice with a plasmid DNA coding for L. infantum chagasi KMP-11 elicited a mixed Th1/Th2-type immune response. However, immunization with the recombinant nanoparticle formulations, in the presence of $\mathrm{CpG}$, induced a significant increase in TNF- $\alpha$ upon restimulation in vitro. Indeed, nanoparticles formulated with DOTAP, the cationic lipid used here, promote a proinflammatory response, with presence of IL-2, IFN- $\gamma$, TNF- $\alpha,{ }^{36}$ and oligodeoxynucleotides, such as CpG motifs, are able to trigger plasmacytoid dendritic cells, resulting in TNF- $\alpha$ production. ${ }^{37}$ Use of DOTAP in our formulations and of $\mathrm{CpG}$ in our immunization scheme may therefore explain the elevated TNF- $\alpha$ levels in immunized mice. We also detected the presence of IgG1 and IgG2a antibodies (Figure 3), suggesting participation of both IL-4 and IFN- $\gamma$ in antibody isotype switching, even though levels of these cytokines were not significantly increased in mice immunized with PLGA nanoparticles (Figure 2).

Following immunization, the mice were challenged with live parasites in the presence of sand fly saliva, mimicking the context of natural infection with 

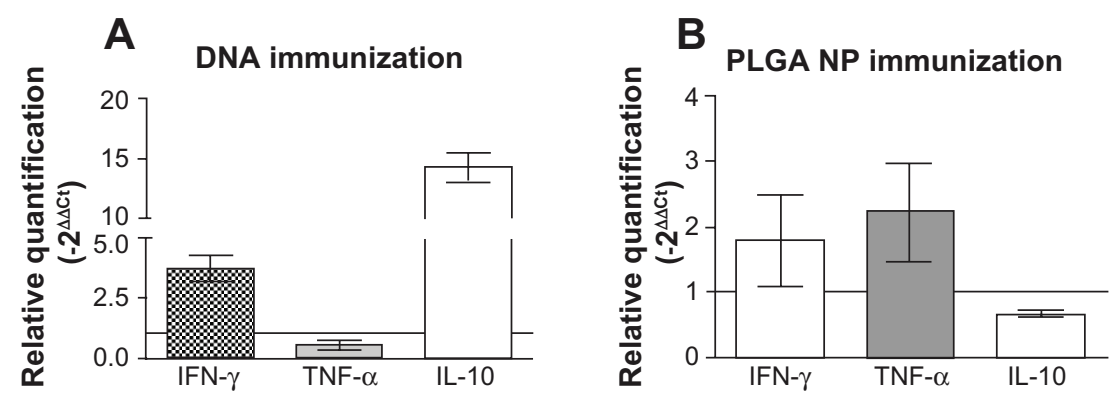

Figure 6 Cytokine expression at the ear dermis following a live challenge with parasites. BALB/c mice were immunized with pcDNA3-KMP-I I (A) or with pcDNA3-KMP-I Iloaded nanoparticles followed by recombinant KMP-I I-loaded nanoparticles + CpG (B).

Notes: Two weeks after the last immunization, the mice were infected with Leishmania braziliensis + salivary gland sonicate. Relative quantification of IFN- $\gamma$, TNF- $\alpha$, and IL- 10 at the infection site was determined 5 weeks after infection, in relation to a housekeeping gene, by real-time polymerase chain reaction (see materials and methods section). Data (mean \pm standard error) are presented as the fold increase in gene expression of immunized mice over control mice and are from two independent experiments.

Abbreviations: KMP-II, kinetoplastid membrane protein- II; PLGA, poly(lactic-co-glycolic acid); NP, nanoparticles: IFN- $\gamma$, interferon gamma; TNF- $\alpha$, tumor necrosis factor alpha; IL-10, interleukin-10.

Leishmania spp. Upon challenge, neither immunization strategy prevented lesion development. Air pouch stimulation with L. braziliensis + L. intermedia saliva enhances CXCL10, CCL2, TNF- $\alpha$, and IL-10 expression, ${ }^{33}$ confirming the immunomodulatory role of saliva from L. intermedia. Although we did not probe for the protective capacity of our immunization strategies in the absence of sand fly saliva, we may speculate that salivary molecules at the time of parasite challenge may have modulated the microenvironment, favoring lesion development.

Despite the inability of the present immunization strategies to prevent disease manifestation, a significant reduction in parasite load was detected at the challenge site. Mice immunized with either DNA alone or with recombinant PLGA nanoparticles displayed increased IFN- $\gamma$ expression at the infection site. Moreover, mice immunized with recombinant PLGA nanoparticles $+\mathrm{CpG}$ also showed elevated TNF- $\alpha$. IFN- $\gamma$ and TNF- $\alpha$ act in concert to activate inducible nitric oxide synthase for the production of nitric oxide, and TNF- $\alpha$ stimulates macrophages to produce nitric oxide. ${ }^{6}$ We can suggest that, in the group immunized with recombinant PLGA nanoparticles, upregulation of IFN- $\gamma$ and TNF- $\alpha$ combined with downregulation of IL-10, may explain the greater parasite killing at the challenge site. In mice immunized with DNA alone, upregulation of IFN- $\gamma$ expression was also observed but was accompanied by a strong elevation of IL-10 expression. Mononuclear cells from patients with leishmaniasis produced high levels of IL-10 upon stimulation with recombinant KMP-11, ${ }^{38}$ whereas addition of recombinant KMP-11 to cells previously stimulated with soluble Leishmania antigen decreased IFN- $\gamma$ secretion. ${ }^{39}$ We could speculate that the immune response induced in DNA-immunized mice may have been more prone to modulation exerted by parasite-derived KMP-11 compared with the response elicited by immunization with PLGA nanoparticles.

Parasite load in the draining lymph nodes was also lower following immunization with either DNA alone or with recombinant PLGA nanoparticles, although differences between the experimental and control groups
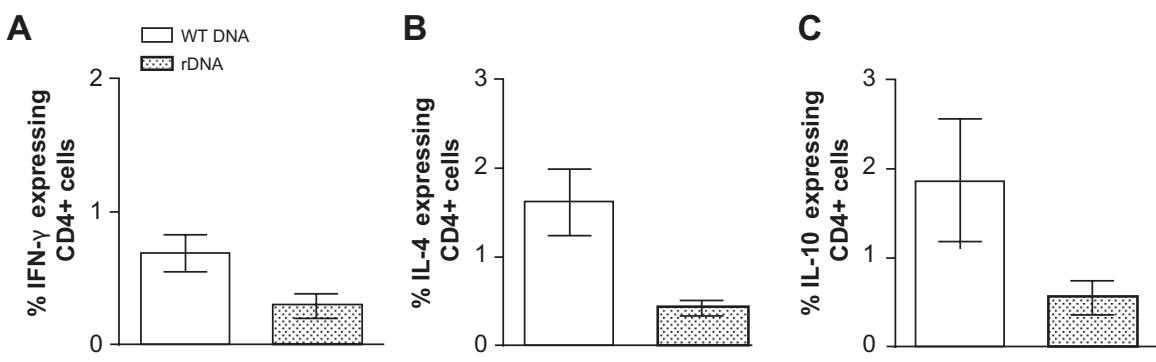

Figure 7 Intracellular cytokine production by CD4+ and CD8+ T cells in mice immunized with a plasmid DNA encoding KMP-II, following a live challenge with parasites. Notes: BALB/c mice were immunized with nonrecombinant pcDNA3 (open bars) or with pcDNA3-KMP-II (closed bars), as described. Two weeks after the last immunization, mice were infected with Leishmania braziliensis + salivary gland sonicate. Five weeks after infection, draining lymph node cells were restimulated in vitro. Data (mean \pm standard error) represent the percentages of CD4+ cells secreting IFN- $\gamma,(\mathbf{A})$, IL-4 (B), or IL-I0 (C) and are from two independent experiments.

Abbreviations: KMP-II, kinetoplastid membrane protein-II; IFN- $\gamma$, interferon gamma; tumor IL-I0, interleukin-I0; IL-4, interleukin-4; WT DNA, nonrecombinant PCDNA3; rDNA, PcDNA3-KMP-II. 

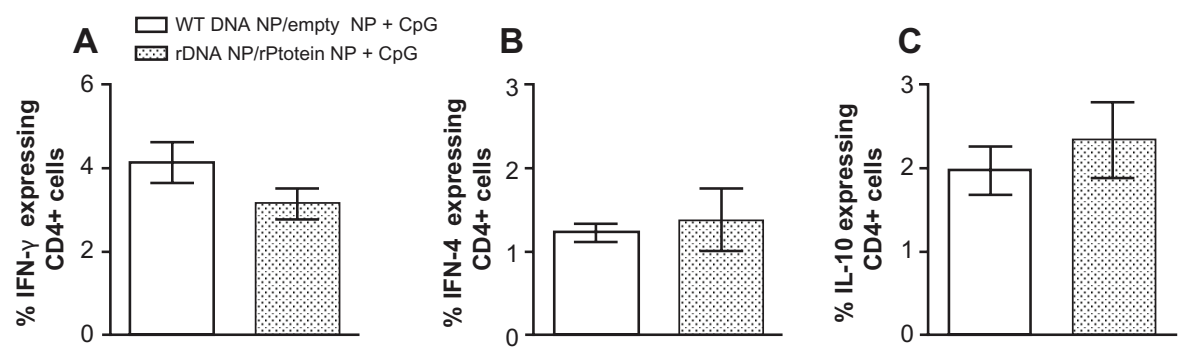

Figure 8 Intracellular cytokine production by CD4+ and CD8+ T cells in mice immunized with the recombinant nanoparticle formulations, following a live challenge with parasites. Notes: Control BALB/c mice were immunized with non-recombinant pcDNA3-loaded nanoparticles followed by unloaded nanoparticles + CpG (open bars). Experimental BALB/c mice were immunized with pcDNA3-KMP-II-loaded nanoparticles followed by recombinant KMP-II-loaded nanoparticles + CpG (closed bars). Two weeks after the last immunization, mice were infected with Leishmania braziliensis + salivary gland sonicate. Five weeks after infection, draining lymph node cells were restimulated in vitro. Data (mean \pm standard error) represent the percentages of CD4+ cells secreting IFN- $\gamma,(\mathbf{A})$, IL-4 (B), or IL-I0 (C) and are from two independent experiments. Abbreviations: KMP-II, kinetoplastid membrane protein-II; IFN- $\gamma$, interferon gamma; tumor IL-10, interleukin-I0; IL-4, interleukin-4; WT DNA, nonrecombinant PcDNA3; rDNA, PcDNA3-KMP-II.

were not significant. One could consider that migration of the effector T cell population (CD4+ IFN- $\gamma+$ ) to the infection site, with parasite killing, explains the lower frequency of cytokine-secreting CD4+ cells in mice immunized with plasmid DNA or with PLGA nanoparticles, when compared with the respective controls. Of note, parasites persist in draining lymph nodes of $\mathrm{BALB} / \mathrm{c}$ mice inoculated with L. braziliensis,${ }^{32}$ despite resolution of dermal lesions and parasite clearance from the infection site. Parasite persistence in cutaneous leishmaniasis has been associated with the presence of regulatory $\mathrm{T}$ cells. ${ }^{40}$ Therefore, another possibility concerns the presence of regulatory $\mathrm{T}$ cells within draining lymph nodes preventing parasite clearance. In the draining lymph nodes, these regulatory $\mathrm{T}$ cells could counteract the presence of effector cells. Indeed, in mice immunized with PLGA nanoparticles, the frequency of CD4+ IL-10+ T cells was elevated in draining lymph nodes.

A stronger immune response is elicited when antigen is associated with particles, compared with soluble antigen alone. ${ }^{41}$ In the case of leishmaniasis, immunization $\mathrm{CpG}$ and PLGA nanospheres loaded with autoclaved L. major was able to decrease $L$. major infection and this effect was associated with increased IFN- $\gamma$ and decreased IL-4 production. ${ }^{21}$ Doroud et al showed that immunization with solid lipid nanoparticles loaded with plasmid DNA coding for Leishmania cysteine proteinase conferred protection against L. major, ${ }^{42}$ and was associated with increased IFN- $\gamma$ levels before challenge and an elevated ratio of IFN- $\gamma / \mathrm{IL}-5$ after challenge. In addition to the choice of antigen and experimental model, several variables such as particle chemistry, size, and surface charge, affect the ensuing immune response, ${ }^{43,44}$ and may explain the different outcomes observed in terms of immunity against leishmaniasis. Of note, we performed experiments in which mice were immunized with naked DNA coding for KMP-11 and were boosted with recombinant KMP-11 + CpG. Following this strategy, mice did not develop a strong humoral immune response, nor was parasite load decreased following a challenge with live parasites (data not shown). Therefore, we can suggest that antigen encapsulation enhanced efficacy of the immune response, possibly by protecting the antigen from rapid degradation and or by ascertaining uptake by antigenpresenting cells, as seen in the present results.

Antigens that have proven effective against $L$. major, such as LACK, LbSTI1, LeIF, and TSA, have not induced similar responses when tested against L. braziliensis. ${ }^{45}$ Vaccination with soluble L. major promastigote exogenous antigens conferred protection against $L$. donovani but also failed to induce a similar response against L. braziliensis. ${ }^{46}$ Since the current findings highlight the need to probe actively for antigens and strategies capable of preventing cutaneous leishmaniasis caused by L. braziliensis, we believe recombinant nanoparticles comprise a platform tailored for such discoveries.

\section{Acknowledgments}

We are grateful to José Carlos Miranda for generously providing the Lutzomyia intermedia salivary glands. This work was supported by grants from CNPq, AECID (Government of Navarra), CAN Foundation and CYTED. DMS, TRD, and KF were supported by CAPES fellowships. MWC was supported by a CNPq fellowship. CB, AB, MB-N, and $\mathrm{CIO}$ are senior investigators from $\mathrm{CNPq}$.

\section{Disclosure}

The authors report no conflicts of interest in this work.

\section{References}

1. Desjeux P. Leishmaniasis: current situation and new perspectives. Comp Immunol Microbiol Infect Dis. 2004;27(5):305-318.

2. Marsden PD. Mucosal leishmaniasis ("espundia" Escomel, 1911). Trans R Soc Trop Med Hyg. 1986;80(6):859-876. 
3. Bittencourt A, Barral-Netto M. Leishmaniasis. Vol 8. 2nd ed. Doerr W, Seifert G, editors. Tropical Pathology. Berlin: Springer; 1995.

4. Alvar J, Yactayo S, Bern C. Leishmaniasis and poverty. Trends Parasitol. 2006;22(12):552-557.

5. Scott P, Natovitz P, Coffman RL, Pearce E, Sher A. Immunoregulation of cutaneous leishmaniasis. T cell lines that transfer protective immunity or exacerbation belong to different $\mathrm{T}$ helper subsets and respond to distinct parasite antigens. J Exp Med. 1988;168(5):1675-1684.

6. Liew FY, Millott S, Parkinson C, Palmer RM, Moncada S. Macrophage killing of Leishmania parasite in vivo is mediated by nitric oxide from L-arginine. J Immunol. 1990;144(12):4794-4797.

7. de Oliveira CI, Nascimento IP, Barral A, Soto M, Barral-Netto M. Challenges and perspectives in vaccination against leishmaniasis. Parasitol Int. 2009;58(4):319-324.

8. Okwor I, Uzonna J. Vaccines and vaccination strategies against human cutaneous leishmaniasis. Hum Vaccin. 2009;5(5):291-301.

9. Ramshaw IA, Ramsay AJ. The prime-boost strategy: exciting prospects for improved vaccination. Immunol Today. 2000;21(4):163-165.

10. Ramiro MJ, Zarate JJ, Hanke T, et al. Protection in dogs against visceral leishmaniasis caused by Leishmania infantum is achieved by immunization with a heterologous prime-boost regime using DNA and vaccinia recombinant vectors expressing LACK. Vaccine. 2003;21(19-20):2474-2484.

11. Dondji B, Perez-Jimenez E, Goldsmith-Pestana K, Esteban M, McMahon-Pratt D. Heterologous prime-boost vaccination with the LACK antigen protects against murine visceral leishmaniasis. Infect Immun. 2005;73(8):5286-5289.

12. Rafati S, Zahedifard F, Azari MK, Taslimi Y, Taheri T. Leishmania infantum: prime boost vaccination with C-terminal extension of cysteine proteinase type I displays both type 1 and 2 immune signatures in BALB/c mice. Exp Parasitol. 2008;118(3):393-401.

13. Gonzalo RM, del Real G, Rodriguez JR, et al. A heterologous prime-boost regime using DNA and recombinant vaccinia virus expressing the Leishmania infantum P36/LACK antigen protects BALB/c mice from cutaneous leishmaniasis. Vaccine. 2002;20(7-8):1226-1231.

14. Tapia E, Perez-Jimenez E, Lopez-Fuertes L, Gonzalo R, Gherardi MM, Esteban M. The combination of DNA vectors expressing IL-12 + IL-18 elicits high protective immune response against cutaneous leishmaniasis after priming with DNA-p36/LACK and the cytokines, followed by a booster with a vaccinia virus recombinant expressing p36/LACK. Microbes Infect. 2003;5(2):73-84.

15. Abdian N, Gholami E, Zahedifard F, Safaee N, Rafati S. Evaluation of DNA/DNA and prime-boost vaccination using LPG3 against Leishmania major infection in susceptible BALB/c mice and its antigenic properties in human leishmaniasis. Exp Parasitol. 2011;127(3):627-636.

16. O'Hagan DT, Rahman D, McGee JP, et al. Biodegradable microparticles as controlled release antigen delivery systems. Immunology. 1991;73(2): 239-242.

17. Carcaboso AM, Hernandez RM, Igartua M, Rosas JE, Patarroyo ME, Pedraz JL. Potent, long lasting systemic antibody levels and mixed Th1/ Th2 immune response after nasal immunization with malaria antigen loaded PLGA microparticles. Vaccine. 2004;22(11-12):1423-1432.

18. Hamdy S, Molavi O, Ma Z, et al. Co-delivery of cancer-associated antigen and Toll-like receptor 4 ligand in PLGA nanoparticles induces potent CD8+ T cell-mediated anti-tumor immunity. Vaccine. 2008; 26(39):5046-5057.

19. Chong CSW, Cao M, Wong WW, et al. Enhancement of Thelper type 1 immune responses against hepatitis B virus core antigen by PLGA nanoparticle vaccine delivery. J Control Release. 2005;102(1):85-99.

20. Doroud D, Zahedifard F, Vatanara A, et al. Delivery of a cocktail DNA vaccine encoding cysteine proteinases type I, II and III with solid lipid nanoparticles potentiate protective immunity against Leishmania major infection. J Control Release. 2011;153(2):154-162.

21. Tafaghodi M, Khamesipour A, Jaafari MR. Immunization against leishmaniasis by PLGA nanospheres encapsulated with autoclaved Leishmania major (ALM) and CpG-ODN. Parasitol Res. 2011;108(5): $1265-1273$.
22. Jardim A, Funk V, Caprioli RM, Olafson RW. Isolation and structural characterization of the Leishmania donovani kinetoplastid membrane protein-11, a major immunoreactive membrane glycoprotein. Biochem $J$. 1995;305(Pt 1):307-313.

23. Jensen AT, Gasim S, Ismail A, et al. Humoral and cellular immune responses to synthetic peptides of the Leishmania donovani kinetoplastid membrane protein-11. Scand J Immunol. 1998;48(1):103-109.

24. Thomas MC, Garcia-Perez JL, Alonso C, Lopez MC. Molecular characterization of KMP11 from Trypanosoma cruzi: a cytoskeletonassociated protein regulated at the translational level. DNA Cell Biol. 2000;19(1):47-57.

25. Basu R, Bhaumik S, Basu JM, Naskar K, De T, Roy S. Kinetoplastid membrane protein-11 DNA vaccination induces complete protection against both pentavalent antimonial-sensitive and -resistant strains of Leishmania donovani that correlates with inducible nitric oxide synthase activity and IL-4 generation: evidence for mixed Th1- and Th2-like responses in visceral leishmaniasis. J Immunol. 2005;174(11): $7160-7171$.

26. Bhaumik S, Basu R, Sen S, Naskar K, Roy S. KMP-11 DNA immunization significantly protects against $\mathrm{L}$. donovani infection but requires exogenous IL-12 as an adjuvant for comparable protection against L. major. Vaccine. 2009;27(9):1306-1316.

27. Costa CH, Peters NC, Maruyama SR, de Brito EC Jr, Santos IK. Vaccines for the leishmaniases: proposals for a research agenda. PLoS Negl Trop Dis. 2011;5(3):e943.

28. Fuertes MA, Perez JM, Soto M, Lopez MC, Alonso C. Calciuminduced conformational changes in Leishmania infantum kinetoplastid membrane protein-11. J Biol Inorg Chem. 2001;6(1):107-117.

29. Fuertes MA, Berberich C, Lozano RM, Gimenez-Gallego G, Alonso C. Folding stability of the kinetoplastid membrane protein-11 (KMP-11) from Leishmania infantum. Eur J Biochem.1999;260(2): 559-567.

30. del Barrio GG, Novo FJ, Irache JM. Loading of plasmid DNA into PLGA microparticles using TROMS (total recirculation one-machine system): evaluation of its integrity and controlled release properties. J Control Release. 2003;86(1):123-130.

31. Iborra S, Carrion J, Anderson C, Alonso C, Sacks D, Soto M. Vaccination with the Leishmania infantum acidic ribosomal $\mathrm{P} 0$ protein plus $\mathrm{CpG}$ oligodeoxynucleotides induces protection against cutaneous leishmaniasis in C57BL/6 mice but does not prevent progressive disease in BALB/c mice. Infect Immun. 2005;73(9):5842-5852.

32. de Moura TR, Novais FO, Oliveira F, et al. Toward a novel experimental model of infection to study American cutaneous leishmaniasis caused by Leishmania braziliensis. Infect Immun. 2005;73(9):5827-5834.

33. de Moura TR, Oliveira F, Rodrigues GC, et al. Immunity to Lutzomyia intermedia saliva modulates the inflammatory environment induced by Leishmania braziliensis. PLoS Negl Trop Dis. 2010;4(6):e712.

34. de Moura TR, Oliveira F, Novais FO, et al. Enhanced Leishmania braziliensis infection following pre-exposure to sandfly saliva. PLoS Negl Trop Dis. 2007;1(2):e84.

35. Livak KJ, Schmittgen TD. Analysis of relative gene expression data using real-time quantitative PCR and the 2(-delta delta $\mathrm{c}(\mathrm{t}))$ method. Methods. 2001;25(4):402-408.

36. Kedmi R, Ben-Arie N, Peer D. The systemic toxicity of positively charged lipid nanoparticles and the role of Toll-like receptor 4 in immune activation. Biomaterials. 2010;31(26):6867-6875.

37. Krug A, Rothenfusser S, Hornung V, et al. Identification of $\mathrm{CpG}$ oligonucleotide sequences with high induction of IFN-alpha/beta in plasmacytoid dendritic cells. Eur J Immunol 2001;31(7): 2154-2163.

38. de Carvalho LP, Soto M, Jeronimo S, et al. Characterization of the immune response to Leishmania infantum recombinant antigens. Microbes Infect. 2003;5(1):7-12.

39. Carvalho LP, Passos S, Dutra WO, et al. Effect of LACK and KMP11 on IFN-gamma production by peripheral blood mononuclear cells from cutaneous and mucosal leishmaniasis patients. Scand J Immunol. 2005;61(4):337-342. 
40. Belkaid Y, Piccirillo CA, Mendez S, Shevach EM, Sacks DL. CD4+ $\mathrm{CD} 25+$ regulatory $\mathrm{T}$ cells control Leishmania major persistence and immunity. Nature. 2002;420(6915):502-507.

41. Singh M, Briones M, Ott G, O’Hagan D. Cationic microparticles: a potent delivery system for DNA vaccines. Proc Natl Acad Sci U S A. 2000;97(2):811-816.

42. Doroud D, Zahedifard F, Vatanara A, Najafabadi AR, Rafati S. Cysteine proteinase type I, encapsulated in solid lipid nanoparticles induces substantial protection against Leishmania major infection in C57BL/6 mice. Parasite Immunol. 2011;33(6):335-348.

43. Rice-Ficht AC, Arenas-Gamboa AM, Kahl-McDonagh MM, Ficht TA. Polymeric particles in vaccine delivery. Curr Opin Microbiol. 2010; 13(1):106-112.
44. Storni T, Kundig TM, Senti G, Johansen P. Immunity in response to particulate antigen-delivery systems. Adv Drug Deliv Rev. 2005;57(3): 333-355.

45. Salay G, Dorta ML, Santos NM, et al. Testing of four Leishmania vaccine candidates in a mouse model of infection with Leishmania (Viannia) braziliensis, the main causative agent of cutaneous leishmaniasis in the New World. Clin Vaccine Immunol. 2007;14(9):1173-1181.

46. Tonui WK, Titus RG. Cross-protection against Leishmania donovani but not L. Braziliensis caused by vaccination with L. major soluble promastigote exogenous antigens in BALB/c mice. Am J Trop Med Hyg. 2007;76(3):579-584.
International Journal of Nanomedicine

\section{Publish your work in this journal}

The International Journal of Nanomedicine is an international, peerreviewed journal focusing on the application of nanotechnology in diagnostics, therapeutics, and drug delivery systems throughout the biomedical field. This journal is indexed on PubMed Central, MedLine, CAS, SciSearch $\AA$, Current Contents ${ }^{\circledR} /$ Clinical Medicine,

\section{Dovepress}

Journal Citation Reports/Science Edition, EMBase, Scopus and the Elsevier Bibliographic databases. The manuscript management system is completely online and includes a very quick and fair peer-review system, which is all easy to use. Visit http://www.dovepress.com/ testimonials.php to read real quotes from published authors.

Submit your manuscript here: http://www.dovepress.com/international-journal-of-nanomedicine-journal 